\title{
Phonology at the boundary of word and phrase: The fleeting vowel of Kashaya evidentials
}

\author{
Eugene Buckley \\ University of Pennsylvania
}

The verb morphology of Kashaya, a Pomoan language of northern California, includes a class of five evidential suffixes. All but one ends in the vowel /a/, whose special behavior is the focus of this paper. A central goal is to lay out the facts clearly and thoroughly, since they are not easily available in existing sources; but I also discuss several possible analyses and their theoretical implications. Section 1 presents the evidential suffixes, illustrating contexts in which the /a/ is present and absent. Section 2 gives the imperative suffixes, while section 3 introduces the clitic / $/$ that accompanies the imperative verbs, and its interaction with the evidentials. Section 4 discusses theoretical issues that arise under various analyses. Section 5 adds some further complications in the data, and a brief conclusion.

\section{Evidential suffixes}

Oswalt (1961) identifies five basic evidential suffixes in Kashaya: FACTUAL - $a$ (-wa after a vowel), VISUAL - $y a$, AURAL -inna, CIRCUMSTANTIAL $-q a$, and QUOTATIVE $-d o{ }^{1}$ The last suffix does not participate in the relevant alternations, and will not be discussed further; but in the four others, the /a/ is deleted wordfinally. Its underlying presence is confirmed by the fact that it surfaces before a following suffix.

Only a few other suffixes can follow the evidentials in the word and thereby preserve the /a/ vowel. These are the RESPONSIVE - em, which indicates that the sentence headed by the verb is uttered in response to a statement or question by someone else; the NOMINATIVE RELATIVIZER -em(u), which marks a relative clause with nominative or "agent" case that serves as the subject of another verb; and the ACCUSATIVE RELATIVIZER -el, which marks a relative clause with accusative or "patient" case that serves as the object

\footnotetext{
* Examples are drawn from Oswalt $(1961,1964)$ and his unpublished dictionary and field notes, housed in the California Language Archive at the University of California, Berkeley, as well as fieldwork by the author. In the orthography used by Oswalt and followed here, $c$ represents the affricate $/ \mathrm{t} /$, dotted $t$ is an apico-alveolar stop, and plain $t$ is lamino-dental; but I deviate from Oswalt in using [:] rather than [·] for vowel length. The phonological analysis is based on Buckley (1994). I am grateful to Anita Silva for her patience and good humor in providing some of these examples, as well as to Akiva Bacovcin, Ricardo Bermúdez-Otero, Dave Embick, John Gluckman, and Kobey Shwayder for discussion of ideas in the paper. This work was partly supported by a grant from the National Endowment for the Humanities: Documenting Endangered Languages program.

${ }^{1}$ Oswalt (1961) classifies two additional suffixes, PERFORMATIVE - ela and PERFORMATIVE COMPLETE -mela, among the evidentials. These suffixes, however, do not have typical evidential meanings: instead they mark a first-person subject along with imperfective and perfective aspect, respectively. Oswalt (p. 246) reasons that "the speaker knows that what he is saying is true because he actually performed the action himself"; and further, since Kashaya does not generally mark person in the verb, it makes some sense to emphasize this evidential aspect. First-person does make another appearance in the Kashaya verb, namely the suffix -wi/-we that in certain contexts marks a first-person object. (In both situations, the subject $-(m) e l a$ and the object $-w i /-w e$, this marking is optional.) The final /a/ of these suffixes also does not show the fleeting behavior found in the true evidentials. In my view, this confirms that the performatives are of a different class. If one were to treat them as the head of an Evidential Phrase (rather than Agreement), then the EvidP analysis in section 4.3 will make the wrong prediction and is not available as an option. The other options discussed there, however, do not generally rely on this classification. The factual and visual are also distinguished by aspect - the first is imperfective and the second is perfective - but they also have clear meaning of the traditional evidential sort, encoding the source of information as visual or other direct experience, and general knowledge (for the factual).
}

(C) 2015 Eugene Buckley

Proceedings of AMP 2014

Completed March 10, 2015. 
(or nonagentive subject) in the larger clause, as well as in locative and other constructions. ${ }^{2}$ These three suffixes are exemplified below with the four evidentials. In all cases, the suffix-initial vowel /e/ deletes by the Elision rule that regularly resolves hiatus.

1.1 Visual -ya I first illustrate the visual, since it is phonologically fairly simple. This suffix "is used for perfective or completed actions which the speaker knows to be true because he saw them happen" (Oswalt 1961: 244). It takes the full form /ya/ when a suffix follows; otherwise the vowel is lost wordfinally and it surfaces as $/ y /$. The evidentials are shown in bold, in both underlying and surface forms.
a. /bati-ya-el/
b. /šiwey-am-ya-emu/
c. /s'i-ya-em/
d. /bacu:m-qa-ya-em/

'where they camped (ACC)'

'the one that is renewed (NOM)'

'(I) did'

'won the game'

'I saw her leach (acorns)'

'I just saw him put (the fire) out'

'I saw it open inward away from me'

'I just saw him drown'

Except in loanwords such as kaho:n 'box', from Spanish cajón, deletion of evidential /a/ is the only source of surface CV:C and CVCC syllables; these are normally resolved by Closed-Syllable Shortening or by Epenthesis (Buckley 1994). Further examples of final CV:C and CVCC, which suggest late application of the vowel deletion, can be seen in the forms below.

1.2 Factual $-(\boldsymbol{w}) \boldsymbol{a}$ This suffix differs partly from the visual on the basis of aspect, since it "is used for imperfective or uncompleted actions being watched by the speaker and also for facts or general truths which are known by everybody to be so, whether or not the action has actually been seen by the speaker." A very similar distribution is found with the factual when added to a vowel-final stem: it surfaces as /wa/ if another suffix follows, and as /w/ word-finally. ${ }^{3}$
a. /da:-wa-em/
b. /mihše-wa-em/
c. /miți-wa-emu/
d. /nohp ${ }^{\mathrm{h}}$ o-wa-el/

da:wam
mihšewam
mițiwamu
nohp ${ }^{\text {howal }}$

da:w

qawi:w hilaya:w sihmohmow
'I want to' '(that) smells (good)'

'the one lying (here) (NOM)'

'where they live (ACC)'

'I want'

'is building'

'the body slips off it'

'(the rain) is breaking up clods (of dirt)'

When the factual is added to a consonant-final stem, an allomorph without the /w/ is used. The corresponding realizations therefore lack this glide, so it surfaces as /a/ when a suffix follows, but as zero word-finally.

\footnotetext{
${ }^{2}$ The nominative relativizer occurs optionally as /emu/ but most often is shorter/em/, in which case it is segmentally homophonous with the responsive. The two suffixes occur in quite different syntactic contexts, however, and the responsive is also accompanied by a distinct rising intonation. Oswalt refers to the case forms as subjective and objective; here I follow the terminology of Deal \& O'Connor (2010) on related Northern Pomo, which has a similar "fluid-S" case system. See Olsson (2010) for more detailed analysis of Kashaya relative clauses.

${ }^{3} \mathrm{The} / \mathrm{w} /$ realization of the factual is segmentally identical to the very common ABSOLUTIVE suffix, which occurs in the same suffix position class and has various functions as the citation form, a matrix verb, an infinitival complement, and a deverbal noun or adjective. They can be distinguished in several ways, however. Phonologically, a long vowel in the final syllable is preserved before the factual but shortens before the absolutive: /da:-w/ yields daw 'to want'. Semantically, the factual is imperfective but the absolutive, when it functions as a verb, is generally perfective. Syntactically, an absolutive verb receives no special marking if other material follows it in the same clause, but as discussed in section 5.2, the factual (like all evidentials) requires the nonfinal verb suffix /e:/.
} 
A stem-final consonant that occurs word-finally is subject to certain changes, such as regular Coda Aspiration of voiceless stops.
a. /țhapbam-a-emu/
b. /di:c'-wac'-a-emu/
c. /bimucid-a-em/
d. /nihcic'-a-em/
e. /phabet-a-el/

(6)

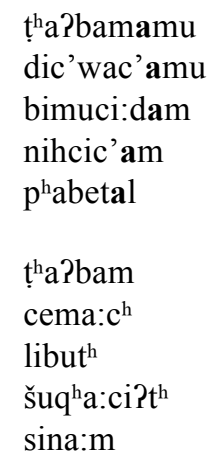

\author{
'what remains (NOM)' \\ 'what they say (NOM)' \\ 'the one who eats (NOM)' \\ '(what are you) talking about' \\ 'what they tied up (ACC)' \\ 'it remains' \\ 'I see it is open inward away from me' \\ 'he is whistling' \\ 'he isn't continuing to saw it off' \\ 'he's drowning'
}

1.3 Circumstantial -qa This suffix "means that the speaker did not see happen what he is telling about but deduced the action from circumstantial evidence," especially "when the evidence is discovered soon after the action or is incontrovertible" (Oswalt 1961: 243). The circumstantial keeps its underlying form /qa/ when a suffix follows, but word-finally it loses the /a/ and the remaining stop undergoes Coda Aspiration to become $/ \mathrm{q}^{\mathrm{h}} /$.
a. /mo:bic-qa-em/
b. /s'i-qa-em/
c. /qane-qa-em/
d. /q'o?di-yic'-qa-em/
e. /hihyuț-ibic-qa-el/

mo:bic ${ }^{\mathrm{h}} \mathbf{q a m}$
s'iqam
qaneqam
q’o?diyic'qam
hihyuți:bic ${ }^{\mathrm{h}} \mathbf{q a l}$

(8)
a. /s'i-qa/
b. /mo-aq-thi-qa/
c. /mo-ht-ac'-qa/
d. /bahțonțolo-c-qa/
e. /sina:m-qa/

s'iq $^{\mathbf{h}}$
moht $^{\mathrm{h}} \mathbf{q}^{\mathbf{h}}$
mohtac' $\mathbf{q}^{\mathbf{h}}$
bahțonțoloc
sinamq $\mathbf{q}^{\mathbf{h}}$

'(she) must have run away'
'(that) must be what happened'
'(they) must have bitten him'
'he must have gotten better'
'where he must have poked around (ACC)'
'it's evident that (you) did'
'he evidently didn't run out'
'they must have been running'
'(the bird) must have pecked it all out'
'he must have drowned'

'(she) must have run away' '(that) must be what happened' '(they) must have bitten him' 'he must have gotten better'

1.4 Aural-inna This suffix "means that the speaker did not see what he is telling about but heard the sounds of the action" (Oswalt 1961: 242). The aural involves several phonological processes. It maintains its final vowel and gemination when another suffix follows; in the available examples, it is the responsive $/ \mathrm{em} /$. When the aural is word-final, the $/ \mathrm{a} /$ is deleted as expected, but this also causes degemination of the consonant, since word-final geminates are prohibited. ${ }^{4}$ Further, this is the only evidential that begins with a vowel when it is added to a vowel-final stem; by regular Elision, the suffix-initial /i/ is deleted (just like suffix-initial/e/ following evidential/a/).
a. /di:c'wac'-inna-em/
b. /hšiyic'-inna-em/
c. /mo:d-inna-em/
d. /s'aya:m-inna-em/

\section{dic'wac'innam \\ šiyi:c'innam mo:dunnam \\ s'aya:mannam}

ba?t'an

cahnon

miq'osmiq'osin

s'aya:man
'I heard them talking'
'I heard him say (that)'
'I heard him run along'
'I hear them making noise'
'it sounds like'
'I hear it barking'
'I hear repeated grunting'
'I hear them making noise'

\footnotetext{
${ }^{4}$ With these changes, the word-final aural patterns as though it had the underlying form /in/, which is identical to the SAME-SUBJECT SIMULTANEOUS switch reference marker; but the latter normally marks a subordinate verb and is frequently followed by other material in the clause, whereas the aural marks a main verb and takes the nonfinal verb suffix /e:/ when it is not final in the clause that it heads (see also the preceding footnote).
} 
When suffix-initial /i/ follows certain consonants, it is subject to other regular changes - in particular, to /a/ after $/ \mathrm{m} /$, and to $/ \mathrm{u} /$ after $/ \mathrm{d} /$ (Buckley 1994), both seen in these examples.

1.5 Fleeting vowels As just demonstrated, all the evidential suffixes containing /a/ also occur without that vowel, specifically when it occurs in word-final context - a notion that will be defined more precisely below. It is crucial to note that similar deletion of a vowel does not occur with any other suffixes; for example, these verb suffixes preserve final /a/.
a. q $^{\text {hade:d-ela }}$
'I've come for it'
(PERFORMATIVE)
b. mu?t'a-phila
'when it's cooked'
(DIFFERENT-SUBJECT FUTURE)
c. dihqa-ba
'after giving'
(SAME-SUBJECT PAST)
d. p pila?-bina
'(that's why) they must have left'
(SUBORDINATE INFERENTIAL)

Final /a/ is also perfectly common among nouns, pronouns, and adjectives, including those that end in sequences identical to the underlying forms of individual evidentials.
a. hi?baya
'man'
b. Pusuwa
'thrush'
c. buțaqa
'bear'
d. maya
'you (PLUR, NOM)'
e. šahya
'fast'

Given the limited application of deletion, it must derive from a special property of evidential suffixes. I refer to these vowels as FLEETING (Russian беглый), inspired by the Slavic yer vowels that are deleted in particular contexts (Timberlake 2004), although these contexts are quite distinct from those in Kashaya.

\section{Imperative suffixes}

2.1 Singular To understand the phrasal context where the fleeting vowel is preserved, we must first be aware of the various imperative suffixes in Kashaya. The most common is the singular imperative /i/, which surfaces unchanged after most consonants but is deleted by Elision after a vowel-final stem. It also undergoes regular changes after certain consonants: to $/ \mathrm{a} /$ after $/ \mathrm{m} /$ or $/ \mathrm{q} /$, and to $/ \mathrm{u} /$ after $/ \mathrm{d} /$. In these examples, boldface indicates the imperative suffix as well as a stem vowel that causes Elision of the suffix, as in (d), so that imperative verbs are more easily identifiable below.

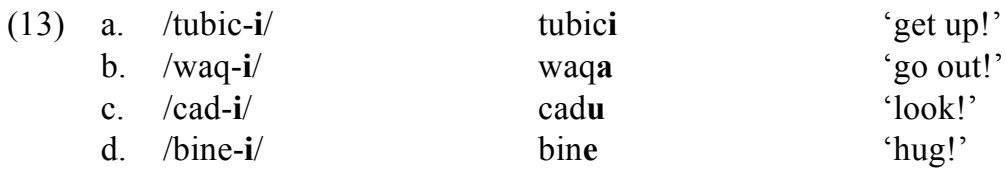

2.2 Negative The negative of the singular imperative has the form $/ \mathrm{t}^{\mathrm{h}} \mathrm{u}$ ?/; as we will see shortly, the final $/ \mathrm{R} /$ is actually a separable element, but this is not evident when the verb is final in its clause. Nonetheless, in anticipation, I mark it as a clitic using the = sign. A stem-final coronal obstruent undergoes reduction before the suffix-initial $/ \mathrm{t} \mathrm{h} /$, but otherwise no special phonology occurs here.
a. /bo?o- $\mathbf{t h}^{\mathrm{h}} \mathbf{u}=\mathbf{2} /$
bo?oth ${ }^{\mathrm{h}} \mathbf{u}$
'don't hunt!'
b. /miced- $\mathbf{t}^{\mathrm{h}} \mathbf{u}=\mathbf{2} /$
mice?t ${ }^{\text {th }} \mathbf{u}$
'don't say it!'
c. /banawac'-qa-ic'-th $\mathbf{t h}^{\mathrm{u}}=\mathbf{2} /$
banawac'qa?th $\mathbf{u}$ ?
'don’t let them deceive you!'

Following Oswalt, we might posit that such verbs include the basic imperative suffix, thus $/ \mathrm{t}^{\mathrm{h}} \mathrm{u}-\mathrm{i}=\mathrm{R} /$, with the /i/ lost by regular Elision. But unlike in other instances of $/ \mathrm{i} /$, the clitic $/ \mathrm{P} /$ is always present with $/ \mathrm{t}^{\mathrm{h}} \mathrm{u} /$. This suggests it might be a distinct negative imperative suffix that patterns with forms such as $/ \mathrm{me} /$ below rather than with $/ \mathrm{i} /$. The preferred analysis will depend on how the divergent behavior of $/ \mathrm{i} /$ is handled, which is a matter I do not pursue here. 
2.3 Plural If the addressee is plural, the imperative is $/ \mathrm{me}=? /$, again with the final $/ \mathrm{P} /$ that will turn out to be a separable clitic. It does not undergo any phonological changes.
a. $/$ Ri-me $=$ ?/
Pime?
'be (still)!'
b /du:cic'-qa-me $=$ ?/
du:cic'qame?
'let (me) know!'
c. /do-ht-ibic-me= $\mathbf{2} /$
dohtibic ${ }^{\mathrm{h}} \mathbf{m e}$ ?
'raise your hands!'

In the negative plural imperative, we see the separate status of the glottal stop in $/ \mathrm{t}^{\mathrm{h}} \mathrm{u}=\mathrm{P} /$, which is found only at the end of the sequence, $/ \mathrm{t}^{\mathrm{h}} \mathrm{u}-\mathrm{me}=\mathrm{?} /$.
a. /lowac' $-\mathbf{t}^{\mathrm{h}} \mathbf{u}-\mathbf{m e}=\mathbf{?} /$
lowa?thume?
'don't talk!'
$\mathrm{b} /$ coq- $\mathbf{t}^{\mathrm{h}} \mathbf{u}-\mathbf{m e}=\mathbf{2} /$
coht ${ }^{\text {h }}$ ume?
'don't shoot!'
c. /hayohm-ala-th $\mathbf{t h}^{\mathrm{h}} \mathbf{u}-\mathbf{m e}=\mathbf{2} /$
hayohmala: $\mathbf{t}^{\mathrm{h}} \mathbf{u m e}$ ?
'don't wander down!'

The element $/ 2 /$ thus occurs exactly once at the end of all the imperative verbs, except with the simple singular $/ \mathrm{i} /{ }^{5}$ Even there, however, we will see that this $/ \mathrm{R} /$ arises when the verb is not final in its clause, i.e. when some material follows the verb. ${ }^{6}$

\section{Imperative clitic}

More-complex sentences show clearly that $/ \mathrm{R} /$ is a clitic: when a phrase follows the verb, it occurs separated from the imperative, and appears in the singular also. (Kashaya is usually head-final, but matrix clauses have flexibility in word order; see Olsson 2010.) We can observe the clitic in sentence pairs that differ in the presence of a post-verbal word, the latter indicated by square brackets.
a. $\quad \mathrm{k}^{\mathrm{h}} \mathrm{e}$ na:waš mis'ita:ma
$k^{\text {he }}$ na:waš mis'ita:ma [to] ?
b. di:c'i?th ${ }^{\text {h }}$ ?
di:c'i?th ${ }^{\text {th }}$ [ma?al] ?
c. pa:nu bihsamme?
pa:nu bihsamme [maya?k $\left.\mathrm{k}^{\mathrm{h}}\right]$ ?
d. ca?thume?
ca?th ume [hayu] ?

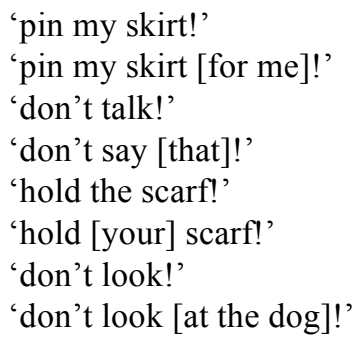

The same alternation is found when the word order changes so that material intervenes between the imperative verb and the end of the clause.
a. [be:li] wa:du
$\sim \quad$ wa:du [be:li] ?
b. [mil] dayec'i
$\sim \quad$ dayec'i $[\mathrm{mil}]$ ?
'come [here]!'
'press your hand [on that]!'

If the last word of the sentence ends in an obstruent, a following / $/$ / is phonologically prohibited and it is deleted, so such forms are not illustrated here.

\footnotetext{
${ }^{5}$ There is also a FORMAL IMPERATIVE /im/ that is largely restricted to traditional texts. This suffix is perhaps the source of more common /i/: in most of the other Pomoan languages, including closely related Southern and Central Pomo, the cognate of Kashaya /im/ is the usual imperative, and it is reconstructable to Proto-Pomo (McLendon 1973, Oswalt 1976). The fairly limited evidence of this suffix in the texts collected by Oswalt (1964) does not make it clear whether /im/ participates in the / $/$ patterning of $/ \mathrm{i} /$ and the other suffixes. (At least in more traditional speech, the plural /me=?/ can also be used formally when the speaker addresses a single in-law.)

${ }^{6}$ Oswalt (1961: 254f) reports that the singular and plural imperatives can be followed by the responsive suffix, and that when this happens, the $/ 2 /$ clitic is absent, whether or not the verb is final in the clause. In the singular, the basic suffix /i/ is followed by /em/, yielding /im/, but also accompanied by the characteristic rising intonation of the responsive. In the plural, the imperative /me/ occurs without any segmental realization of the responsive, just the intonational rise. I have not identified such forms in my own fieldwork.
} 
3.1 Other imperatives For completeness, I illustrate a special subcase of the singular imperative involving the suffix /we/; Oswalt glosses it "hither" but it typically indicates a first-person object (direct or indirect). As mentioned for $/ \mathrm{t}^{\mathrm{h}} \mathrm{u} /$ above, we would expect $/ \mathrm{we}-\mathrm{i} / \mathrm{with}$ inclusion of the regular singular imperative to surface as /we/ by Elision, so that /we-i=?/ is a possible analysis.

\begin{tabular}{|c|c|c|}
\hline a. $/$ ho-we $=$ ?/ & $\begin{array}{l}\text { howe? } \\
\text { tumbuwe? }\end{array}$ & 'give me (in a container)! \\
\hline $\begin{array}{l}\text { /tumhu-we=?/ } \\
/ \text { daba:ne-we=? }\end{array}$ & $\begin{array}{l}\text { tumhuwe? } \\
\text { daha·newe? }\end{array}$ & ‘buy it for me!' \\
\hline
\end{tabular}

$$
\begin{array}{ll}
\text { a. } & \text { qaya?tawe [yal] ? } \\
\text { b duhye:ciwe [to] ? } \\
\text { c. suhțawe [to] [?a:the] ? }
\end{array}
$$

'share food [with us]!'

'keep [me] company!

'open it [for me], [Mother]!'
a. [to:] dihqawe?
$\sim$
dihqawe [to] ?
b. [mul] q'a:we? $\sim$ q'a:we [mul]?
'give it [to me]!'
'leave [that] here!'

Example (20c) illustrates the fact that more than one constituent can follow the imperative verb, but the clitic occurs only after the last one. ${ }^{7}$

There is also an idiosyncratic imperative verb /te?/, meaning 'give!', that shows unique behavior. When not final in its clause, it takes the sentence-final clitic $/ 2 /$; but the $/ 2 /$ at the end of the verb is not identifiable with that clitic, since it remains even when the verb is nonfinal.
a. [to:] te?
$\sim \quad$ te? [to] ?
'give it [to me]!'
b. te? [mul] ?
'give [that] here!'

Essentially, /te?/ patterns like simple imperatives with /i/, insofar as the / $/$ clitic is added at the end of the sentence when the verb is not final, but the verb itself does not change its form according to position. ${ }^{8}$

3.2 Longer material In addition to the rather short words illustrated so far after the imperative verb, it is possible for longer elements such as an object, locative, relative clause, or adjunct to occur there.
a. da?k'ath ${ }^{\text {h }}$ [mul wenta:na] ?
b. Pahqha qane [mi?khe k'ața] ?
'don't push and crack [that window]!'
c. kalikak ${ }^{\text {h }}$ dahša? bawili [milu: kaho:n li] ?
d. du?k'u [ma Pama: cic'i:dal] ?
'soak [your clothes] in the water!'
'put the papers loose [in the box there]!
e. dohtibich me [muhk ${ }^{\text {h }} u n a c$ 'qaw ?t $^{\text {hin }}$ ] ?
'finish [what you're doing]!'
f. bis'i:ci [ma:kina tol bit'el? wa:yi] ?
'raise your hand [without being bashful]!'
g. yohwe: qowi:lac'me [maya hit'et ${ }^{\mathrm{h}} \mathrm{p}^{\mathrm{h}} \mathrm{i}$ ] ?
'baste it [before sewing it on the machine]!'
'okay, return home [when you're ready]!'

Full embedded clauses - those with an independent subject and inflected verb - also occur in this position. These full clauses are followed by the imperative clitic/R/, which is present only because of the larger imperative context: it does not occur if the embedded clause is used as an independent sentence.
a. waht ${ }^{\text {h }} \mathbf{u}$ [mi:li] [ma?c'ane: mi:li] ?
b. Pana: to q'o?di ca?t ${ }^{\text {h }} \mathbf{u}$
[pihțanțalac' $k^{\text {he }}$ thin $^{\text {e to: }} \mathrm{ma}$ ] ?
c. qali to: min ț'a:ci
[bahcil hla hi?s'ila:du:s'uwe] ?

\footnotetext{
${ }^{7}$ A few examples in the corpus have two clitics, each occurring at the end of a different subordinate clause, where the speaker seems to have decided to add more information. This may be a disfluency or a repair; or it may be the only means of accommodating multiple subordinate clauses occurring after the imperative.

${ }^{8}$ This /te?/ is distinct from the PERFORMATIVE INTENTIVE suffix, translated 'I/we will' or 'let's', which is -te? when clause-final and -te elsewhere. Despite the familiar alternation, / $/$ is absent with -te and does not surface clause-finally.
} 
3.3 Imperatives with evidentials We come now to the interaction of the evidential vowel with the imperative clitic. If the embedded clause following an imperative verb ends in an evidential verb, the final /a/ is not deleted; in other words, the clitic/?/ prevents it from being "final", just like a suffix does.

a. /cad-u da:-wa/ $\rightarrow$ cadu da:w

b. taq ${ }^{\mathrm{h}} \mathrm{ma}$ še:du [cadu da:wa] ?
a. /Panaw qa?c'at-a/ $\rightarrow$ Pana: qa?c'at th $^{\mathrm{h}}$
b. nața Pel bine [?ana: qa?c'ața] ?
a. wa:du [?ul hit'ehya] ?
b. moya:du [ciba: thin mi: Pinna] ?
c. mu:kito bahnat ${ }^{\mathrm{h}} \mathrm{qa}$
[?ihche dibu? min ba?t'awa] ?
d. Pana: mi?k ${ }^{\mathrm{h}}$ k'ața šohp ${ }^{\mathrm{h}} \mathrm{hhp}^{\mathrm{h}} \mathbf{o t}^{\mathrm{h}} \mathbf{u}$
[?ul ma šahțanțala:ya] ?

\author{
'I want to see' \\ 'come here wearing the dress, [I want to see it]!' \\ 'he's crying a lot' \\ 'hug the child, [he's crying a lot]!' \\ 'come on, [it's ready]!' \\ 'go look, [it sounds like someone is there]!' \\ 'ask him, \\ [it sounds like it's raining]!' \\ 'don't shake your clothes so much; \\ [you've already faded them]!'
}

Again, the presence of the imperative clitic has no direct relation to the verb that is marked with an evidential: the embedded clause has no imperative meaning or morphology. Rather, the evidential verb just happens to be immediately followed by the imperative clitic because of the larger sentential context.'

\section{Implications}

It is the preservation of $/ \mathrm{a} /$ in this context that raises the issue of particular interest. As shown in section 1 , the fleeting /a/ has a special lexical or morphological status, distinct from other tokens of /a/. This suggests its fate should be decided in a "lexical" or analogous part of the derivation, depending on one's specific approach. But whether it deletes depends on the potential presence of an imperative clitic unrelated to the evidential verb; this, in turn, makes crucial reference to the location of the evidential word in syntactic structure, and word-internal information is generally thought to be unavailable there. In other words, we need reference to the special property of evidentials, but in a way that is plausibly available in the phrasal representation. I consider here several possible solutions, and their relative (dis)advantages.

4.1 Morpheme-specificity Slavic yer vowels are a useful analogy to the Kashaya alternation, since they similarly involve vowels that sometimes appear but are sometimes deleted, and it is a lexical property of some roots and suffixes but not others. Gouskova (2012) argues that giving Russian yers a special phonological representation, such as different features or the lack of a mora, fails to account for two basic generalizations: only mid vowels show fleeting behavior, and only in the last syllable of a morpheme. As a result, she argues that the exceptionality is associated not with the segment but with the entire morpheme.

As with the Russian yers, a distinct representation of fleeting /a/ in Kashaya (like that proposed by Buckley 1994) fails to account for the very restricted distribution of these vowels: they occur in exactly four suffixes, all of which belong to the evidential class. This observation, in fact, takes us a step further than is possible in Russian, where members of the same morphological class (such as common nouns) differ arbitrarily in this property.

Suppose that in Kashaya the class of evidential suffixes is subject to morpheme-level exceptionality. This could be higher ranking of a constraint against /a/ final in a Prosodic Word (PrWd), or idiosyncratic triggering of Final-a Deletion, $/ \mathrm{a} / \rightarrow \varnothing / \ldots)_{\mathrm{PrWd}}$. The problem is that this morpheme-specific triggering of a rule would have to be available in the postlexical or phrasal component of the grammar - a more powerful theory than what is needed to account for Russian yer deletion, which requires only word-internal

\footnotetext{
${ }^{9}$ This /a/ deletion appears to be an innovation in Kashaya. The most closely related languages, Central and Southern Pomo, have cognate evidential suffixes that retain the /a/ even when sentence-final: for example, Southern to: $m u$ :to da:wa 'I like him' (from Oswalt's manuscript dictionary; see also Walker 2013). The separability of the imperative clitic, on the other hand, is shared by Central Pomo, at least with regard to the plural /me?/; Southern Pomo has no clear cognate of this suffix (Oswalt 1976).
} 
information. Such rich phrasal representations predict quite powerful interactions between apparent phrasal rules and the internal morphemic content of words. With this power, however, the approach does correctly limit the exceptionality to the segments that are located within the morpheme class in question, without predicting effects on other morphemes within the word or phrase.

4.2 Rule activation A somewhat different approach to rule-triggering by a morpheme in a larger phrase comes from Embick (2010). In his model, word-internal idiosyncrasies can refer to specific morphemes; but phrasally, any special properties are associated with the word or even the phrase through the mechanism of ACTIVATION. He proposes that an eventual operation can be "turned on" at one point in a derivation, but will not have an opportunity to apply until a later point. In Kashaya, the rule would be Final-a Deletion without any reference to the special status of evidentials. At the point in the derivation where the identity of the evidential suffix is available - such as immediately upon suffixation - this rule is activated by the suffix, or by the class to which the suffix belongs. More specifically, some diacritic feature is inserted that later triggers the deletion rule, which applies in a noncyclic rule block after the clitic is present. This would be analogous to a [+foreign] category, but limited to words with particular triggering morphemes.

An advantage of this approach is that the rule formulation is strictly phonological, without a need to refer to the identity of the evidential suffix or other special status of the vowel at the time of application. Because the rule is activated for the entire representation, however, it predicts broader effects. For example, a rule that is activated in this manner might be triggered by one set of suffixes but apply to other parts of the word; it would seem to permit a scenario in which the evidentials activate a rule of place neutralization, so that final $/ \mathrm{m} /$ becomes $/ \mathrm{n} /$ in the presence of those suffixes, but otherwise remains unchanged. In fact, as formulated, Final-a Deletion ought to apply to $/ \mathrm{a} /$ at the end of an evidential verb whether or not that vowel arises from an evidential suffix. This is not testable in Kashaya, but seems to predict an unlikely grammar.

A related question is how long rules can remain activated in this manner; for example, the activation might last just until the first noncyclic round of rule application, which would include clitics. Even if we were to choose an arbitrarily distinguished segment $/ \mathrm{a}_{2} /$ as the trigger in Kashaya, word-level rules are a plausible limit on the availability of this distinction.

4.3 An Evidential Phrase As discussed previously, fleeting /a/ is specifically restricted to evidentials; it is not a property of four random suffixes, and does not require an arbitrary diacritic associated with a list of morphemes, much less particular tokens of /a/. To capture this generalization, we can appeal to work in syntax that has argued for the existence of an Evidential Phrase (Cinque 1999, Tenny 2006): it provides us with exactly the structure that will distinguish fleeting /a/ from other tokens of the same vowel. In this analysis, the special behavior comes not from the vowel itself (with distinct featural or prosodic specification), nor from the morpheme or word (with some kind of exceptionality toward a rule or constraint), but from the syntactic phrase in which it is located.

Assume that the evidential suffix is the head of the EvidP, and is rightmost in the phrase. The evidential /a/ is always final in that phrase, so occurrence in the position _ ] EvidP is not a sufficient condition for deletion, since of course it sometimes surfaces intact. Rather, the EvidP is the means of distinguishing the fleeting /a/ from other final tokens of this vowel, which never undergo deletion. For the additional condition, we can appeal again to the prosodic structure, since what simple suffixes like the responsive share with the imperative clitic is that they are integrated into the prosodic word with preceding material. So an /a/ that is identified as final in the EvidP will undergo deletion only if it is also final in the prosodic word. That is, it must satisfy two conditions.

(28) a. Morphosyntactic condition

b. Phonological condition

$$
\begin{aligned}
& ]_{\text {EvidP }} \\
& -)_{\text {PrWd }}
\end{aligned}
$$

The following representations illustrate sentences in which the phonological context for deletion is not satisfied $(29,30)$, and is (31). I make no commitments here regarding the full morphosyntactic structure.
a. hite:t] ya $]_{\text {EvidP }}$ ?]
b. $\quad\left((\text { hi })_{\sigma}(\text { teh })_{\sigma}(\text { ya? })_{\sigma}\right)_{\text {PrWd }}$

\author{
'(come on,) it's ready!' \\ no deletion: not final in PrWd
}




\author{
'the one lying (here) (NOM)' \\ no deletion: not final in PrWd
}

'he must have drowned'

$\rightarrow$ sinamq $^{\mathrm{h}}$

This approach requires simultaneous access by the rule to a morphosyntactic boundary as well as a prosodic boundary. By referring to the EvidP rather than the identity of the final suffix, however, it avoids the problem of reaching into a word at a point in the derivation where such information is usually seen as unavailable in a restrictive theory. Since the analysis depends on a very particular aspect of the Kashaya pattern, however, it may not be applicable to similar phenomena in other languages.

4.4 Feature passing Bermúdez-Otero \& Payne (2011) discuss several patterns in which phrasal clitics interact with lexical properties. For example, the English possessive 's is generally pronounced [Iz] following singular nouns ending in a sibilant, as in Mr. Katz's /kætsız/ name; but following a plural, it has a zero realization, as in the cats' $/ \mathrm{kæts} /$ names. This is true even when the immediately preceding word is not the possessor: for most speakers, 'the house of a man who owns cats' is the man with the cats' /kæts/ house, rather than $/ \mathrm{kætsiz} /$. The issue is that the plurality of cats is not a property of the phrase to which the possessive is added: it is headed by man, which is singular. Yet the zero realization of the possessive depends on access to the fact that the final /s/ of the phrase is a plural suffix; otherwise it ought to be realized as with Katz.

Bermúdez-Otero \& Payne (p. 80) observe that such cases seem to show that "the postlexical morphophonology must be able to look inside a grammatical word in order to determine the morphological affiliation of its final segment." That is very much what we find in Kashaya, since the rule of Final-a Deletion needs to know if the /a/ belongs to an evidential suffix. Their solution for English, in a stratal model, is to permit FEATURE PASSING between the head of a phrase and its edge; the possessive is directly suffixed to cats in the lexical derivation, where it is realized as zero; but postlexically the genitive feature is passed to the phrase headed by man. In this way, the word cats' is realized as if the possessive applied directly to it, and indeed that is its morphological history; but the feature instantiated by the zero possessive is ultimately associated with the larger phrase in which it is located, and this yields the correct semantic interpretation. The phonological effect is generated in the lexicon (by suffixation), but feature passing allows the possessive meaning to shift postlexically to the right level of structure.

In Kashaya, the analogous approach would be to treat the imperative clitic $/ \mathrm{R} /$ as a suffix expressing the imperative mood, in multiple exponence with suffixes such as plural imperative $/ \mathrm{me} /$. The presence of the clitic blocks Final-a Deletion in the lexicon, just as more conventional suffixes like the responsive do. Postlexically, because this evidential-imperative word is final in the phrase, the morphosyntactic mood feature is passed up to the larger phrase, where it appropriately combines with the features arising from suffixes on the head verb such as $/ \mathrm{me} /$. That leaves the embedded evidential with its remaining features, excluding the imperative.

Interestingly, treating / $/$ / as a suffix even when it occurs separated from the imperative verb provides a satisfying account of the fact that it has no realization immediately after the affirmative singular imperative suffix /i/: it is quite common for an allomorphic alternation to make reference to the stem to which it attaches. But if the $/ 2 /$ is treated as a prosodically defective word that is absent, or zero, when it immediately follows a singular imperative, then this allomorphy is more surprising.

\section{Remaining questions}

5.1 Previous analysis Oswalt (1961), working in a structuralist theory, posits a variety of morphophonemes whose phonemic realization depends on the environment. For example, the fleeting vowel is represented as \|ă $\|$, a segment that is realized as /a/ if another vowel follows, and as zero if a word boundary follows. This segment occurs only in evidential suffixes, as one would expect based on the preceding discussion; but the analysis gives no principled reason for this limited distribution. In my analysis, a process of $/ \mathrm{a} /$ deletion is responsible for the zero realization of that vowel word-finally, and various ways of accounting for the limitation to evidential /a/ were discussed in section 4 . 
To prevent deletion of the vowel before the imperative clitic /R/, Oswalt (1961:290) proposes a special suffix, the explanatory $\|\hat{e}\|$, "which forms a subordinate adverbial clause and only occurs in a sentence containing one of the Imperative suffixes. The clause explains or gives the reason for the command." This approach requires that every sentence in which an evidential verb follows the imperative contain the explanatory suffix, whereas I have tried to derive the behavior of the fleeting vowel strictly from independently motivated facts of the prosody and morphosyntax. The explanatory meaning would arise simply from the position after the imperative verb, without special marking, exactly as in English translations such as 'hug the child, he's crying a lot', where 'because' is not overt.

Oswalt's explanatory suffix $\|\hat{e}\|$ has exactly two realizations. When it is preceded by an evidential suffix, it is zero; that is a regular property of this morphophoneme, equivalent to Elision after a vowel, and it serves only to prevent deletion of the /a/ by making it nonfinal. The other realization is /e/. Oswalt states that this suffix "is only added to suffixes of Class v14aV", which is his label for the evidentials. But he also includes examples of the suffix immediately following the ASSERTIVE / $/$, a defective verb permitting certain suffixes that is often involved in copular sentences, and here it is realized on the surface as /e/. ${ }^{10}$
a. men s'ith ${ }^{\mathrm{h}} \mathbf{u}[\mathrm{ko}: \mathrm{ko}$ ?e] ?
b. soh q'aci [mul] [pišudu ?e] ?
c. pikeli [mul] [?ana: qa?s'o ?e] ?
'don't do that; [it's taboo]!'
'just leave [those] behind; [they are no good]!'
'straighten [that], [it's really dented]!'

It turns out, however, that the explanatory has the same surface form that one would expect of the nonfinal verb suffix /e:/, which occurs with the assertive to produce the extremely common copular form /?e:/. The following imperative clitic / $/$ / will trigger Closed-Syllable Shortening, so that / $\mathrm{P}-\mathrm{e}: \mathrm{P} /$ becomes /Re?/, just as posited / -e ?/ would. Thus, under an analysis that does not make use of an explanatory suffix, an alternative view of these sentences is simply that they contain a copula with the basic meaning 'be'.

The next section considers this nonfinal verb suffix in more detail.

5.2 Nonfinal verbs The nonfinal verb suffix /e:/ "occurs whenever a main verb which would otherwise end in an Evidential or Modal suffix is not final in the sentence. Its only significance seems to consist of indicating which is the main verb in such circumstances" (Oswalt 1961: 282). It is specifically required after evidentials and modals (the latter are not illustrated here); other verbs do not take an indication of nonfinality. Before this suffix, the fleeting /a/ is lost in favor of the long vowel; with the circumstantial, regular lowering to /a/ occurs after/q/. Note here each of the four evidential suffixes.
a. ku:ška ya? muhtenhma-y-e: [šoq'o? daceti]
b. sapa:tu šuhlahla-w-e: [mi?k $\left.{ }^{\mathrm{h}} \mathrm{e}\right]$
c. šaluwah-q-a: [mito]
d. baq'o thin cutanc-inn-e: [be: hePey ?t $^{\text {thin] }}$
'the cat jumped across [to catch a mouse]' '[your] shoes are shiny' '[you] evidently failed to catch any (fish)' 'something slammed [somewhere back here]'

Since phonological evidence shows that /e:/ syllabifies in the same word as the stem to which it is attached (Buckley 1994), it would be difficult to explain the deletion of /a/ here by arguing that the evidential is final in a Prosodic Word. It might be the case that the /e:/ features dominate because they are associated with an underlyingly long vowel. Alternatively, this might be a place to exploit simple morpheme exceptionality, since this fact does not interact with phrasal phonology. ${ }^{11}$

Although the nonfinal verb suffix, as one would expect from the name, does usually have following material in the sentence, it sometimes occurs finally, especially in colloquial questions (with rising intonation) and less often in statements. Such examples may reflect a change in progress, i.e. an innovative use of the suffix.

\footnotetext{
${ }^{10}$ The assertive is no doubt derived historically from the root / $\mathrm{i}$ / 'be', but it shows distinct synchronic patterning. The first example shown is explicitly presented by Oswalt (1961) as consisting of the assertive plus the explanatory; the other examples are drawn from his corpus and would presumably be given the same analysis.

${ }^{11}$ Indeed, the peformative suffixes - $(m)$ ela (see footnote 1 ) do preserve their vowel features before the nonfinal verb suffix, i.e. /ela-e:/ $\rightarrow$ /ela:/, just as they do not lose their /a/ word-finally.
} 
(34) a. wa:du da:-w-e:

b. he?en ța ma phak'uma:c'-e:

c. mito Pihyumci-y-e:

(35) a. Pana: c'iškan qa?t'a-w-e:

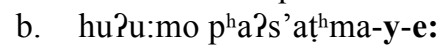

'do you want to come?'

'how did you kill it?'

'did you get cold?'

'it tastes wonderful'

'he slapped (her) face'

The assertive plus the nonfinal verb suffix - the copula /?e:/ mentioned in the previous section - might be analyzed as containing the factual $-a$, that is / $-\mathrm{a}-\mathrm{e}: /$, with a zero realization as expected with the following suffix; the semantics of that evidential are consistent with the general use of this copula. These examples illustrate its use outside the imperative context.
a. q'ordi ?e: [mu]
b. hayu re: [mu]
c. sipba ?e: [?a] [mito]
d. qowe:cic'k ${ }^{\text {he }}$ ?e: [?a]
e. duk'uma?chi ?e: [ninec'k $\left.k^{\mathrm{h}} \mathrm{e}\right]$
'[he] is good'
'[that] is a dog'
'[I] am in debt [to you]'
'[I] am going to come back here'
'it is by tiring practice that [(you) will learn]'

As with other uses of the nonfinal verb, when combined with the assertive it can occur in final position, whether in a question or a statement.

(37) a. wini ?e:

b. cahno ba?lu ?e:

(38) a. ?a ?e:

b. ma?u Pama: Pihmi dic'i:duwa:du ?e: 'is she pregnant?'
'is he mute?'
'it's me'
'this is a true story'

Let us return now to Oswalt's explanatory suffix realized as /e/. In the examples that have a following imperative clitic, producing / $\mathrm{e}$ ?/ as in (32), I posit that the clauses occurring after the imperative verb have a structure like those in (38), with shortening of /e:/ by regular process. As a result, I do not include an explanatory suffix in my analysis. Where it is zero, that means Final-a Deletion (or the equivalent) has applied; where it is /e/, it actually is the nonfinal verb suffix.

Still open is the question of whether the imperative clitic causes the preceding verb to count as "nonfinal"; we have just seen that the use of the nonfinal verb is broader than its basic definition implies, and it also has a copular use in final position. A fuller understanding of the nonfinal verb suffix must await future research.

5.3 Prosodic phrase The sentences presented in section 3 illustrate by far the best attested pattern: an imperative verb followed by a clause that ends in an evidential verb, followed by the imperative clitic. In this case the clitic causes the preservation of the evidential /a/. But at least two sentences in the corpus appear to have the same preservation of the fleeting vowel with a word (underlined) intervening between the evidential verb and the imperative clitic.
a. Poho wi phe uk'ili [ša?q'ammawa mi] ?
'point the light at it; [it's dark there]!'
b. Šudahchi [mul Pacac' el] [cana:wiya yal] ?

It is possible that these small elements, /yal/ 'us' and /mi:/ 'there', are incorporated into the same Prosodic Word as the evidential verb, in which case preservation of /a/ is entirely expected; or it may be that finality with respect to a larger constituent, the Prosodic Phrase, is the right formulation. Since we have been dealing almost entirely with Prosodic Words that are final in the sentence, they are necessarily also final within larger prosodic categories. These two sentences are unusual, however, because the nonfinal verb suffix would normally occur here if these were matrix clauses; and further, Olsson (2010) observes that all the subordinate clauses he examined are verb-final, unlike in (39). Given the small number of examples available, the right analysis is unclear. 
Another sentence with unexpected preservation of /a/ is found in Oswalt's (1961) original description of the explanatory suffix; here he provides two word orderings with the same meaning.
a. šoci [cáhnowa] ?
'listen, [he's singing]!'
b. [cahnowá] šoci
'[he's singing], listen!'

Order (a) is common, and the kind that I have analyzed in this paper. Order (b), however, is the only example I have of its kind; it shows preservation of $/ \mathrm{a} /$ from the factual at the end of what would seem to be a Prosodic Word. (There is no imperative clitic in (b) because the singular imperative /i/ is sentence-final.) Once again, it may be that the relevant prosodic domain for /a/deletion is a Prosodic Phrase of some kind, and interesting support for this idea comes from metrical structure. It is well established that stress in Kashaya is often calculated over two or more words (Buckley \& Gluckman 2012). I have included the accent marks in these sentences because they show that the two words, in both orderings, are grouped together into a single phrasal metrical domain, with stress on the third syllable of the domain in each case. ${ }^{12}$ It is possible that the domain for stress assignment is the same as the domain for preservation of fleeting $/ \mathrm{a} /$.

Nevertheless, since these examples are few in number and unusual in other ways, motivation for formulating deletion at the end of a domain larger than the Prosodic Word remains relatively weak.

5.4 Conclusion In this paper I have illustrated the behavior of the fleeting /a/ vowel that is part of four evidential suffixes in Kashaya, including the interaction of its deletion pattern with the presence of the clitic $/ 2 /$ in imperative sentences. This pattern raises interesting questions about the possible interaction of idiosyncratic lexical information, morphosyntactic categories, and phonological alternations that apply to phrasal domains. Additional research is necessary to shed light on the diverse ways in which the realization of morphemes in the language is sensitive to whether a verb is final in the clause or sentence.

\section{References}

Bermúdez-Otero, Ricardo \& John Payne. 2011. There are no special clitics. In Morphology and its interfaces, 57-96, ed. Alexandra Galani, Glyn Hicks \& George Tsoulas. Amsterdam: John Benjamins.

Buckley, Eugene. 1994. Theoretical aspects of Kashaya phonology and morphology. Stanford: Center for the Study of Language and Information.

Buckley, Eugene \& John Gluckman. 2012. Syntax and prosody in Kashaya phrasal accent. U. Penn Working Papers in Linguistics 18, 21-30.

Cinque, Guglielmo. 1999. Adverbs and functional heads: A cross-linguistic perspective. Oxford University Press.

Deal, Amy Rose \& Catherine O’Connor. 2010. The perspectival basis of fluid-S case-marking in Northern Pomo. In Proceedings of SULA 5: Semantics of Under-Represented Languages in the Americas, University of Massachusetts Occasional Papers 41, 173-188, ed. Suzi Lima. Amherst: GLSA.

Embick, David. 2010. Stem alternations and stem distributions. Ms., University of Pennsylvania.

Gouskova, Maria. 2012. Unexceptional segments. NLLT 30, 79-133.

McLendon, Sally. 1973. Proto-Pomo. (UCPL 71.) University of California Press.

Olsson, Bruno. 2010. Subordinate clauses in Kashaya Pomo. Thesis, Stockholm University.

Oswalt, Robert L. 1961. A Kashaya grammar (Southwestern Pomo). PhD dissertation, University of California, Berkeley.

Oswalt, Robert L. 1964. Kashaya texts. (UCPL 36.) University of California Press.

Oswalt, Robert L. 1976. Comparative verb morphology of Pomo. Hokan Studies: Papers from the First Conference on Hokan Languages, 13-28, ed. Margaret Langdon \& Shirley Silver. Mouton.

Tenny, Carol L. 2006. Evidentiality, experiencers, and the syntax of sentience in Japanese. Journal of East Asian Linguistics 15, 245-288.

Timberlake, Alan. 2004. A reference grammar of Russian. Cambridge University Press.

Walker, Neil Alexander. 2013. A grammar of Southern Pomo: An indigenous language of California. PhD dissertation, University of California, Santa Barbara.

\footnotetext{
${ }^{12}$ Although third-syllable stress is the default in Kashaya when the second syllable is light, example (40a) would actually be expected to have second-syllable stress because the first word has a monosyllabic root/šoc/ and does not normally permit extrametricality (Buckley 1994). By itself, however, /cahnowa/ would not normally have initial stress, and so the default pattern appears to have been applied to the entire phrase.
} 